\title{
The Research of Financial Forecasting and Valuation Models
}

\author{
Ziliang Shang ${ }^{1}$ \\ ${ }^{1}$ Graduate School of Management, Clark University, Worcester, MA 01610, USA \\ Corresponding Author's Email:Ryanshangzl@163.com
}

\begin{abstract}
Financial analysis has always been a particular focus of scholars around the world. With the development of economy, domestic and foreign scholars continue to improve their financial analysis methods. However, there are few literatures to study the development process of financial analysis and the important factors that affect enterprise value. Based on this situation, this paper systematically reviews and sorts out the relevant research results of the origin and the development of the financial analysis. Then it introduces the driving factors of the enterprise value from financial and non-financial aspects and the valuation methods that are concerned mainstream. At the end of this paper, it raises potential problems with current mainstream valuation methods by comparing the calculated results with the actual results and put forward the possible improvement direction to solve these problems. Hope this paper can provide useful reference for scholars to further study this problem.
\end{abstract}

Keywords: Financial analysis, value drivers, valuation models

\section{INTRODUCTION}

With the establishment and improvement of China's market economic system, the requirements for enterprise behavior are becoming more and more standardized and scientific. Financial analysis is an important way to evaluate the operating conditions of enterprises. It evaluates and analyzes leverage, asset management, profitability and solvency of the enterprises. Financial analysis is not only the summary of completed financial activities, but also the premise of financial forecast, playing a role of connecting the preceding and the following in the cycle of financial management. It is of great significance to carry out the work of financial analysis deeply.

However, at the present stage, there are still many problems in the financial analysis of China, affecting the financial analysis function in practical work. Financial statements reflect the historical operation of an enterprise based on historical data, which is lagging. In our rapidly changing society, the results of analysis only based on historical data are certainly unsatisfactory. At the same time, with the interaction among the upstream manufacturers, the middle suppliers, and downstream customers more and more, the management and development of the company also need to gradually broke the boundaries of the company itself. The company needs to carry on the whole network or the whole process management with wider scope and deeper value chain. Unfortunately, the current financial analysis is still difficult to break through the boundaries of enterprises and make an overall analysis from the perspective and thinking of the whole value chain and industry chain. To understand these problems and improve them is the direction that financial analysts should work hard for.

\section{THE DEVELOPMENT OF FINANCIAL FORCASTIN AND VALUATION MODELS}

\subsection{Budding Period of Financial Analysis}

The budding period of financial analysis started from the American banking industry at the beginning of 20th century and ended with the emergence of the concept of financial statements in 1919. Financial analysis in western countries started from the credit investigation conducted by bank capitalists on enterprises. The banks that issue loans took the analysis of financial statements as a technical means to investigate the operation stability of enterprises that received loans. In 1900, American scholar, Thomas Uduro, first put forward the concept of financial analysis in the Railway Report Decomposition and made a systematic study of a series of basic concepts of financial and accounting statement analysis. In 1919, 
American financial scholar Alexander Wall wrote Ratio Analysis System. A series of books, such as Novi Bell's Profit and Loss Analysis Chart and Stefan Gill's Trend Analysis, have further enriched and developed the theories and methods of financial statement analysis. All these indicate that financial statement analysis has been formed as a relatively independent discipline. ${ }^{[1]}$

\subsection{Development Period of Financial Analysis}

With the deepening of the practice of financial analysis, financial analysis has entered the development stage, which lasted from 1920 to the end of the 20th century. At this stage, American scholars put forward a series of single financial analysis methods. For example, Alexander Wall proposed the most primitive ratio analysis system. However, the ratio analysis cannot reflect the corresponding relationship between the ratio and balance sheet. To remedy this deficiency, James h. Bliss(1923) and Stephen(1925) put forward comparative analysis method and trend analysis method respectively, which added many other single financial indicators. They tried to use industry average and dynamic financial data to better reflect the operating results of enterprises. Regrettably, these financial analysis methods only have single indicative and cannot comprehensively analyze the financial situation of enterprises. Therefore, scholars began to put forward a comprehensive financial indicator system. American DuPont scholars Pierre DuPont and Donaldson Brown (1919) put forward the DuPont analysis system, which can deeply analyze and compare the business performance of enterprises, promote the operational efficiency of the company's assets and maximize the benefits of shareholders. ${ }^{[2]}$

Although the financial analysis method has developed from single financial analysis index to comprehensive financial analysis index, the comprehensive financial analysis index also has some limitations. Then, Alan J.Marcus(1992) and Krishna g. Palepu(2000) improved the indicators of DuPont analysis method respectively. Alan J.Marcus disintegrated some indicators of DuPont analysis method at a deeper level and studied the application of financial leverage in DuPont analysis method. Replacing ROE with sustainable growth, Krishna g. Palepu invented The Palepu system, which is one of the four financial ratio analysis indicators currently used.

The traditional analysis of driving factors of enterprise value is based on financial indicators, which reflect historical information with lag and fail to reflect the future prospects of the enterprise. It may lead managers to violate the long-term strategy of the organization for short-term interests. At the same time, the traditional financial analysis is not related enough to the enterprise goal. It ignores the internal and external relations of enterprises and is difficult to meet the needs of strategic decision-making and operation management.
Because there are many defects in financial indicators, it has gradually become a consensus in academic circles to reform them.

\subsection{Progressive Maturation Period of Financial Analysis}

In the late 20th century, financial analysis reached a mature stage. Scholars have put a lot of effort into predicting future financial conditions. In 1990, Stern Stewart Consulting Company first proposed EVA performance evaluation indicator. The innovation of EVA lies in the comprehensive consideration of the cost of capital of the enterprise and adjusts the profit obtained according to GAAP from the fundamental purpose of enterprise value appreciation. So it can evaluate the enterprise performance more accurately. Focusing on corporate cash flow, American scholar Pewa(1999) systematically introduced the basic principles of cash flow, the skills of cash management, the influence of options and derivatives on cash flow and the comparative analysis of cash flow statements. Charles Gibson(2002) believes that Increasing the attention to the changes in cash flow can timely detect problems in the daily operation of the enterprise.

In addition, because financial indicators cannot meet the needs of financial analysts and corporate stakeholders under the principal-agent system, scholars improved Economic Added Value by integrating value management and strategic management ideas and proposed Balanced Score Card. Merton Miller and Franco Modiani(19581961) put forward the theory of economic value added (EVA). It is not a simple accounting profit, but an economic profit considering the opportunity cost of capital, eliminating the distortion of traditional financial indicators in a certain extent. Then, Harvard University professors, Robert and David(1992), put forward the balanced scorecard under the guidance of the two core concepts of Strategic View and Balanced View. They added three non-financial indicators, which are customer, internal business process, and learning and growth, on the basis of former financial index as a strategic analysis tool used to a comprehensive enterprise management. In addition, Kaplan and Norton(2000) put forward the concept of strategy map, which helps BSC transform strategic vision into measurable organizational and personal indicators and realize the strategic management function of BSC. ${ }^{[3]}$

with good foresight and value correlation, nonfinancial index is attracting more and more attention as the innovation of traditional enterprise value analysis. Scholars believe that non-financial indicators can make managers' behaviors consistent with the priority strategies of the organization, thus promoting the implementation of corporate strategies and the improvement of business performance. However, there are also problems to be improved, such as the lack of executable theoretical 
guidance for the selection of assessment indicators, the unknown determinants of the quality of non-financial indicators, and the lack of detailed research on the weight allocation of performance indicators.

\section{THE DRIVING FACTORS OF ENTERPRISE VALUE}

From the perspective of enterprise value creation, the value driving factors can be divided into financial driving factors and non-financial driving factors by combining the operation and financial aspects. Financial driving factors are applicable to a wide range of analysis methods because their data are easy to obtain and the analysis process is relatively simple. However, it can not directly help the management to make business decisions. And financial value drivers do not focus on long-term value growth, but focus on short-term business performance, which is prone to short-sighted behavior. Non-financial indicators can measure the process indicators of the implementation of various behavioral processes to achieve results and they are convenient for enterprises to allocate resources effectively. Therefore, it is not comprehensive to study enterprise value only by financial analysis. Non-financial value drivers are also essential in the study of value drivers. ${ }^{[4-5]}$

\subsection{Financial Drivers}

From the perspective of enterprise value creation, the value driving factors can be divided into financial driving factors and non-financial driving factors by combining the operation and financial aspects. Financial driving factors are applicable to a wide range of analysis methods because their data are easy to obtain and the analysis process is relatively simple. However, it is not comprehensive to study enterprise value only by financial analysis, and non-financial value drivers are also essential in the study of value drivers. Non-financial indicators can measure the process indicators of the implementation of various behavioral processes to achieve results, which is convenient for enterprises to allocate resources effectively. At the same time, we can use the valuation model to determine the value of the existing variables to help predict the future trend and solve the possible problems. ${ }^{[6]}$

\subsubsection{Liquidity}

Solvency analysis refers to the analysis of the ability and security degree of an enterprise to repay various debts. It can effectively reveal the financial risks of enterprises. The index of analyzing the long-term solvency of enterprises mainly includes asset-liability ratio. Analyzing the short-term solvency of enterprises mainly focuses on studying the relationship between current assets and current liabilities of enterprises, as well as the changes of related projects. The financial indicators for analyzing and evaluating the short-term solvency of enterprises mainly include current ratio, quick ratio, etc.

\subsubsection{Asset management}

The operating capacity of an enterprise reflects the capital turnover situation of an enterprise. The analysis of this indicator can show the operating situation of an enterprise and its management level. If the capital turnover is good, it means that the enterprise has a higher level of operation and management and a higher efficiency of capital utilization. The operation capability analysis of an enterprise is also a financial analysis of the capital turnover of an enterprise. Its purpose is to reveal the level of operation and management of an enterprise in an all-round way. The efficiency of using various assets and the speed of turnover of an enterprise are directly related to its debt paying ability and profitability. Therefore, the operating ability of an enterprise reflects its operating performance. A detailed analysis of the operating capacity of the enterprise can help investors, creditors and operating managers have a deeper understanding and mastery of the solvency and profitability of the enterprise and make an objective, comprehensive and fair evaluation of the business performance. The analysis of operating capacity is achieved through the analysis of a series of turnover indicators, such as accounts receivable turnover, inventory turnover, total assets turnover and fixed assets turnover, etc.

\subsubsection{Profitability}

Profit is the basic material guarantee for the continuous survival, operation and development of an enterprise. It is not only closely related to the interests of investors, but also closely related to the interests of creditors, managers and other relevant parties. The analysis of the profitability of the enterprise is generally the analysis of the main business activities of the enterprise. Some abnormal or special business activities will not be taken into consideration as a kind of sustainable profitability in the analysis. The performance of an enterprise's profitability is mainly based on the analysis of the enterprise's operating income, expenses, investment income, profit, net interest rate on sales, return on equity and other indicators and comprehensively judge, analyze and evaluate the profitability of an enterprise.

\subsubsection{Growth ability}

The growth ability of the enterprise refers to the ability of the enterprise to grow continuously in the process of carrying out a series of business activities. If the enterprise want to survive, stand firm, grow in the unpredictable market changes and keep their advantages 
in the commercial era with rapid technological innovation, they need to continuously expand the production scale in order to better cope with the competition risks in the market. Managers of enterprises should not only focus on the growth of quantity, but also keep the concept of long-term development of enterprises in their mind. The indicators to analyze the growth ability of an enterprise mainly include the growth rate of main business income, the growth rate of net assets, the growth rate of total assets and the growth rate of net profits.

\subsection{Non-financial Drivers}

There are many factors that can influence the future development of the financial, including customer satisfaction, quality of products and services, the company strategic target, the potential development ability, innovation ability, market share, etc. However, manpower, enterprise architecture, innovation ability as well as the supply chain relationship are more important compared with others. ${ }^{[7]}$

\subsubsection{Reserve of talents}

For enterprises, human capital is the accumulated assets of employees' knowledge, which is the competence knowledge of enterprise management team. This competency knowledge mainly includes the employee's educational background, work experience, industry experience, specialized skills and work attitude. Therefore, in the context of research-driven enterprise value creation, human capital should take the lead and become the primary consideration of non-financial driving factors. In terms of human capital research, it can be summarized into four indicators: employee knowledge, employee experience, employee attitude and employee ability.

\subsubsection{The structure of capital}

Structural capital is the knowledge resources contained in the organizational structure. It is the basic framework of an enterprise and the overall system and process for an enterprise to solve problems and create value. Structured capital has organizational integrity, specificity, and can be copied and shared, belonging to the whole enterprise. It can activate and catalyze human capital, make human capital give full play to and rely on enterprise platform, and promote the accumulation of structural capital. When we study the structural capital which drives the non-financial value of enterprises, we mainly analyze it from four index dimensions: business process, information system, organizational structure and enterprise culture.

\subsubsection{Strategic relationship}

Analyzed from the business level, relational capital is the identification relationship formed in the long-term cooperation between an organization and other external stakeholders. It is the knowledge attached to the relationship, with specificity and uniqueness. Relational capital constantly adds value through operation and investment and brings new competitive advantages to the organization. From the difference between the enterprise and other cooperative objects, the relationship capital can be considered from the following relationships: customer relationship, distributor relationship and supplier relationship, strategic partnership relationship, shareholder relationship and creditor relationship.

\subsubsection{Innovation}

Only when investment and innovation collide can the spark of wisdom be touched. The condensation between them can finally become the innovation capital of enterprises. This kind of knowledge-based innovation capital mainly includes four index dimensions: innovation ability, innovation achievement, innovation mechanism and innovation culture. The continuous practice of innovation capital in enterprise operation can make the quality of products and services respected by customers, meet the new needs of consumers, and constantly drive the value creation of enterprises.

To sum up, among the non-financial value drivers, human capital is like a foundation stone, without which it is like a house without a foundation; Structural capital is the glue that integrates human capital. Innovation capital is the driving force factor, which directly determines the ability and duration of sustainable development of enterprises. Relational capital is like a window connected with the outside world, and external direct transaction cooperation. Only by giving full play to the synergistic effect of these four factors can the internal value of the enterprise be better driven and the value of the enterprise be increased and maintained continuously.

\subsection{The valuation methods}

At present, the mainstream valuation methods in China include the comparable company method and the discounted cash flow method. Also, there are a small number of researchers use the option pricing model to measure the company value. The next part focuses on these three valuation methods and discusses their advantages and disadvantages as well as their possible applicability. ${ }^{[8]}$

\subsubsection{Relative valuation methods}

Relative valuation method, also known as market method or comparable company method, is an indirect evaluation method. The specific process refers to 
selecting similar industries as benchmarks and conducting direct or analogy analysis on target enterprises. The evaluation process of relative valuation method is relatively simple and easy to use. Commonly used relative valuation methods include the price-toearnings ratio $(\mathrm{P} / \mathrm{E})$ and the price-to-book ratio $(\mathrm{P} / \mathrm{B})$.

\subsubsection{P/E ratio method}

The $\mathrm{P} / \mathrm{E}$ ratio method usually selects the average $\mathrm{P} / \mathrm{E}$ ratio of several companies in the same industry to estimate the value of the enterprise. Then estimates the enterprise value according to the earnings per share of the enterprise. The specific formula is as follows:

Enterprise value $=$ the selected industry average $\mathrm{p} / \mathrm{e}$ ratio * be evaluated enterprise's earnings per share

The $\mathrm{P} / \mathrm{E}$ ratio method is typically used for consistently profitable industries and for companies that are unlisted or have just gone public. From the calculation formula, the $\mathrm{P} / \mathrm{E}$ ratio method is simple to operate and the required data is easy to obtain. The $\mathrm{P} / \mathrm{E}$ ratio method considers the profit level of the enterprise, reflecting the relationship between investment and income. However, the $\mathrm{P} / \mathrm{E}$ ratio method also has great limitations. Firstly, this method requires that enterprises have the ability of continuous profitability. For enterprises with negative earnings, the estimated results are meaningless. Secondly, there is a high requirement for the selected enterprises. Even if the same industry, business model, management level and so on are not the same, so the analogy estimation has a certain subjectivity; Finally, the P/E ratio method is not only affected by the enterprise's own profit level, but also affected by the overall economic situation. When the economy is booming, the assessed value will be overestimated. And when the market is in recession, the estimated value will be underestimated.

\subsubsection{P/B ratio method}

Similar to the $\mathrm{P} / \mathrm{E}$ ratio method, the $\mathrm{P} / \mathrm{B}$ ratio method is more reflected in the net assets of the enterprise. The higher the net assets of the enterprise, the higher the evaluated enterprise value. The specific calculation formula is as follows:

Enterprise value $=$ the selected industry average $\mathrm{p} / \mathrm{b}$ * be evaluated enterprise net assets per share

Unlike the $\mathrm{P} / \mathrm{E}$ ratio, the net assets of general enterprises are positive, which can be used for most enterprises. In addition, compared with the net income, the net assets are not easy to be manipulated artificially and the changes in the net assets of enterprises can well reflect the changes in the value of enterprises. Similarly, both the $\mathrm{P} / \mathrm{B}$ and $\mathrm{P} / \mathrm{E}$ ratios methods select analogical enterprises. In this respect, the evaluation results are not objective enough. In addition, enterprises adopt different accounting standards, the performance of net assets is different. The analogy does not constitute objectivity. Finally, for some industries with low net assets, such as high-tech industries and service industries, the $\mathrm{P} / \mathrm{B}$ method is used to underestimate the enterprise value. ${ }^{[9]}$

To sum up, the advantages of relative value method are: calculation is simple and the principle is easy to understand. As long as the financial data of the target enterprise is obtained from the relevant database and network, there is no need to carry out too much technical analysis and prediction. Therefore, the relative value method is considered to be a simple, fast and low technical risk value assessment method. However, its shortcoming lies in that it does not take into account the operational differences among enterprises. So the estimation results are not objective enough and may be greatly affected by the value of the analog enterprises.

\subsubsection{Relative valuation methods}

The absolute valuation method, also known as the discount method, is the value of the enterprise based on the evaluation of the operating level of the enterprise. It refers to the future expected earnings of the enterprise discount to obtain the existing value of the enterprise. Absolute valuation method generally includes two methods: economic value added method(EVA) and discount cash flow method(DCF).

The idea of the discounted cash flow method is to sum up the discounted value of the cash flow generated by the company's assets in the future period to calculate the present value of the enterprise. Depending on the category of cash flow, the discounted cash flow method can be divided into equity discount model and free cash flow model. And according to the category of the free cash flow, the latter can be divided into equity free cash flow discount model and free cash flow discount model. The free cash flow discount model is the most common form of DCF model valuation model. However, DCF valuation model is very technical. In the process of valuation, it is necessary to determine the forecast period, discount rate and cash flows in the forecast period. Therefore, DCF valuation model inevitably has some subjective factors of the evaluator. And the selection of parameters will directly affect the accuracy of the final valuation results.

\subsubsection{Option pricing model valuation method}

At present, the option pricing model valuation method has also formed a relatively perfect calculation method system. Besides the commonly used binary tree at present, it also includes finite difference method and Monte-Carlo simulation method. The finite-difference method starts from the final moment of the validity of the option and uses the numerical iterative method to push back to the initial moment of the option(Hull and White, 1990). It is very suitable for the pricing of American options. But its 
disadvantage is that it is not good at dealing with the pricing of path-dependent options and high-dimensional options. Monte-Carlo simulation is a widely used numerical method at present. Boyle(1997) used the Monte-Carlo simulation method for option pricing. He pointed out that the variance reduction techniques can improve the computation efficiency of the Monte-Carlo simulation method. Then he used standard Monte-Carlo simulation method and modified Monte-Carlo simulation method, which combined the dual variables technology and control technology, to price the European call option with dividends. The least-square Monte-Carlo simulation method proposed by Longstaff and Schwartz (2001) is also an important research direction for pricing American options. ${ }^{[10]}$

At present, the valuation process in China usually uses the DCF method to initially estimate the value of the target company. Then adjusts the measured results through the comparable company method. The option simulation method is relatively more accurate for the valuation of enterprises and can freely increase or decrease the variables that need to be paid attention to. It is usually used for some industries with insufficient historical data or special industries, such as various emerging industries. However, option pricing model is morecomplex compared with other methods. It is rarely used in China at present.

\section{THE VALUATION OF NAURA USING DCF MODEL}

The next part will select a listed company for valuation analysis and find possible problems and possible directions for improvement for current valuation methods by analyzing the reason of the different between the measured results and the actual results. ${ }^{[1-13]}$
NAURA is a large comprehensive high-tech company with specialized electronic equipment and electronic components as its main products, integrating research and development, production, sales and service. The company is China's largest electronic equipment production base and high-end electronic components manufacturing base. Research and development products are widely used in semiconductor, photo-voltaic, lithium battery and other emerging industries as well as precision instruments, automatic control and other fields.

There are many possibilities for the company's future growth. Company's 2020 incentive program will fall to the ground, which is beneficial to realize the technological breakthrough and the long-term development, the IC equipment revenue will breakthrough point of profit, and the company will accelerate the growth in IC equipment and photovoltaic equipment fields. Referring nearly two years of revenue growth and important financial ratios of the company, the DCF model, which is used to calculate the company's stock price at end of 2020, makes the following assumptions:

The company will go through three different stages of revenue growth. The first, a five-year high growth period of $40 \%$ revenue growth since 2020 ; the second, revenue growth geometric slowed to $6 \%$ over the next six years; the third, a $6 \%$ growth in a sustainable growth period. EBITDA accounting for $15 \%$ of operating revenue. The enterprise income tax rate is levied at $20 \%$ according to the current regulations of the state. The discount rate is $10 \%$, referring to the average capital cost of current market enterprises. The cash assets and long-term liabilities in the 2020 annual report is same with the data in the 2019 annual report. The results are as follows:

Table 1 DCF results

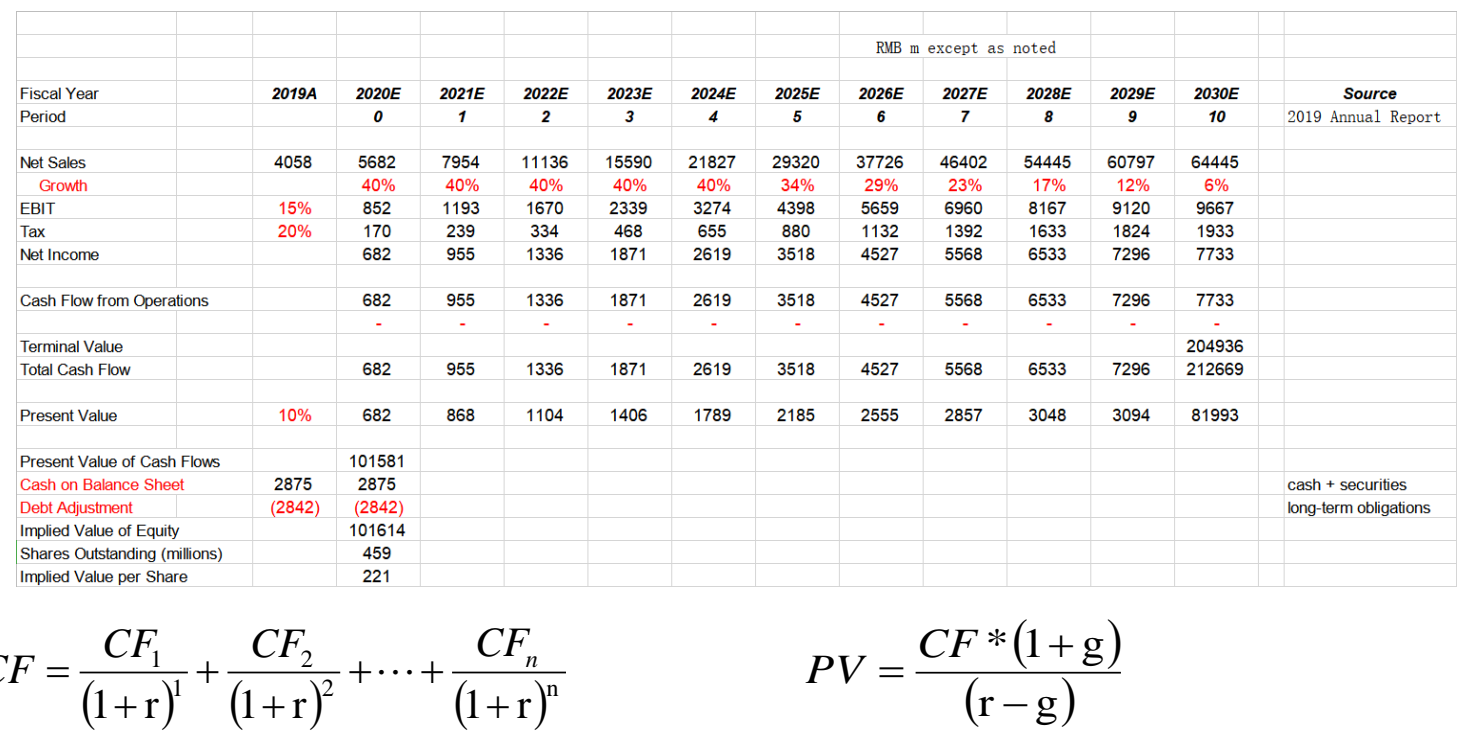

$\mathrm{CF}=$ The cash flow for the given year. 
$\mathrm{CF}_{1}$ is for year one, $\mathrm{CF}_{2}$ is for year two, $\mathrm{CF}_{\mathrm{n}}$ is for additional year

$$
\begin{aligned}
& r=\text { the discount rate } \\
& \mathrm{g}=\text { sustainable growth rate }
\end{aligned}
$$

According to the calculation results, the target price of NAURA by the end of 2020 is 221 yuan and its actual closing price on December 31, 2020 is 180.74 yuan. There are three possible reasons for such a big difference between the estimated results and the actual price. First, the actual growth rate of domestic and even global economy is much lower than expected due to the impact of COVID-19. The company's revenue growth in 2020 is lower than expected. Second, in 2020, the United States carried out a targeted attack on China's chip industry. The company's main business is in the field of semiconductor equipment, which has a close relationship with the chip industry. So it may be greatly impacted. Third, in order to stimulate economic growth, various countries have adopted the means of increasing money supply to stimulating economic growth, resulting in a wide range of fluctuations in the benchmark interest rate and thus affecting the valuation of companies.

The traditional discounted cash flow model and comparable company method cannot take into account the impact of systemic risk in valuation. In fact, there were already signs of COVID-19 outbreak in early 2020. If a parameter can be set in the valuation process to reflect the possible impact of COVID-19 to the economy, the valuation results can be more accurate.

\section{CONCLUSION}

Using financial statements to summarize the operating results of an enterprise in the past period, to evaluate the current financial situation, and to predict the future operating performance plays a particularly important role in the process of business decision-making and enterprise development. However, the traditional financial analysis and valuation models cannot meet the needs of strategic decision-making and operation management in the context of the rapid development of information and data due to insufficient correlation with enterprise goals and neglect of internal and external connections of enterprises. The future development direction of financial analysis may need to pay more attention to the data analysis of the upstream and downstream value chain of enterprises. In that way, financial analysis may better break through the limitations of financial statements, integrate internal and external relations of enterprises, and enhance the correlation with enterprise goals. Then improve the guiding role of financial analysis in business decisions.

Of course, the financial analysis based on value chain Of course, the financial analysis based on value chain lacks the source of reliable data under the current accounting theory and is limited by the current accounting system. At the same time, the specific value chain of different industries is also very different. So, it is difficult to summarize a set of standard evaluation system. Future research could go further in this area.

\section{REFERENCES}

[1] Toms. Railway Report Decomposition[J]. America, 1900.

[2] Pierre DuPont, Donaldson Brown. The DuPont System[M]. Kessinger Publishing, 1919.

[3] YANDAVA KARUN KUMAR,V.V.S. KESAVA RAO. DEVELOPMENT OF BALANCED SCORE CARD FRAMEWORK FOR PERFORMANCE EVALUATION OF AIRLINES[J]. International Journal of Management (IJM),2019,10(6).

[4] Arthur L.Thomas, The Allocation Fallacy and Financial Analysis, Financial Analysts Journal, September-October 1975, 37-41

[5] LinZ H, Guo T T.Financial Quality Evaluation of Listed Companies Based on Factor Analysis Method[J].Applied Mechanics and Materials,2013.

[6] Nicholas S. P. Tay, Dilip K. Das, Lee Yao, Pisun $\mathrm{Xu}$. Economic and Financial Drivers of Growth[J]. Chinese Economy,2012,45(4).

[7] Andrea Masini, Emanuela Menichetti. Investment decisions in the renewable energy sector: An analysis of non-financial drivers[J]. Technological Forecasting \& Social Change, 2013, 80(3).

[8] Robert C Higgins. Analysis for Financial Management. Science\&Culture publishing House (H.K), 2000.

[9] Harlan D Platt, Marjorie B Platt. Predicting Corporate Financial Distress: Reflections on Choice-based Sample Bias.of Economics and Finance.[M].2002,18--25

[10] Birge, J., \& Zhang, R.. Risk-neutral Option Pricing Methods for Adjusting Constrained Cash Flows. The Engineering Economist. 1999, 44(8): 39 49.

[11] Andrew B.Abel, Janice C.Eberly. Investment, Valuation and Growth Options [J]. Journal of Finance, 2003, 54(5): 1553-1607.

[12] Copeland. The Measurement and Management of Company Value[M]. Encyclopedia of China Publishing House, 1998, (2):137 - 138.

[13] Lxxmpkin, Gregory G Dess. E-Business Strategies and Internet Business Models: How the Internet Adds Value[J] . Organization Dynamics 5-2012(2). 